\title{
Experimental studies on the effect of the enhancemet of the heating surface on the heat transfer coefficient for boiling in closed volume
}

\author{
Mirosław GRABOWSKI, Ewelina BŁACHNIO
}

DOI: 10.30464/jmee.2018.2.2.121

Cite this article as:

Grabowski M., Błachnio E. Experimental studies on the effect of the enhancemet of the heating surface on the heat transfer coefficient for boiling in closed volume. Journal of Mechanical and Energy Engineering, Vol. 2(42), No. 2, 2018, pp. 121-130.

\section{VOLUME 2(42) | No. 2 | JUNE 2018}

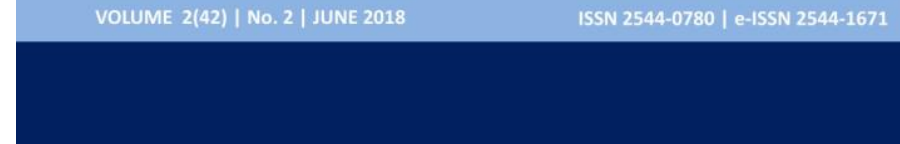

Journal of

MECHANICAL and ENERGY ENGINEERING

Editor-in-Chief

Waldemar Kuczyński

Editors

Krzysztof Rokosz | Krzysztof Nadolny
Journal of Mechanical and Energy Engineering

Website: jmee.tu.koszalin.pl

ISSN (Print): 2544-0780

ISSN (Online): 2544-1671

Volume: 2(42)

Number: 2

Year: 2018

Pages: $121-130$

Article Info:

Received 4 April 2018

Accepted 25 May 2018

\section{Open Access}

This article is distributed under the terms of the Creative Commons Attribution 4.0 (CC BY 4.0) International License (http://creativecommons.org/licenses/by/4.0/), which permits unrestricted use, distribution, and reproduction in any medium, provided you give appropriate credit to the original author(s) and the source, provide a link to the Creative Commons license, and indicate if changes were made. 


\title{
EXPERIMENTAL STUDIES ON THE EFFECT OF THE ENHANCEMET OF THE HEATING SURFACE ON THE HEAT TRANSFER COEFFICIENT FOR BOILING IN CLOSED VOLUME
}

\author{
Mirosław GRABOWSKI $^{1 *}$, Ewelina BŁACHNIO ${ }^{2}$ \\ ${ }^{1 *}$ Warsaw University of Technology, Institute of Mechanical Engineering, Plock Campus, ul. Łukasiewicza \\ 17, 09-400 Płock, Poland e-mail: miroslaw.grabowski@pw.edu.pl \\ ${ }^{2}$ Warsaw University of Technology, Institute of Mechanical Engineering, Plock Campus, Poland
}

(Received 4 April 2018, Accepted 25 May 2018)

\begin{abstract}
This article presents the results of experimental research on the effect of enhancing the heating surface on the heat transfer coefficient for boiling in a closed volume of ethyl alcohol and isopropyl alcohol. The aim of the research was determination of the impact of heat surfaces enhancements by applying circular cavities on heat transfer coefficient and on vapor structures formation during boiling. The study involved three brass samples with diameters equal to $50 \mathrm{~mm}$, with different enhancements of the heating surface by drilled blind cavities. The research includes investigation of sample without cavities, sample with 133 circular cavities of diameter of $2 \mathrm{~mm}$ and sample with 61 circular cavities of diameter of $3 \mathrm{~mm}$. On the basis of the research, the influence of the investigated heat exchange surface enhancement on the intensity of heat exchange was determined. The author's own interface in the LabView environment for controlling and acquiring measurement data was developed. The boiling process was recorded with a high-speed camera, and based on the obtained video images, the recorded images were analyzed to determine the void fraction. The heat flux density, heat transfer coefficient were calculated and comparative diagrams of the obtained measurement results were made.
\end{abstract}

Keywords: boiling, boiling on enhanced surfaces, heat transfer coefficient, intensification of heat exchange, LabView

\section{INTRODUCTION}

An increase of the heat transfer coefficient at boiling can be obtained by active or passive methods. For economic reasons, taking into account energy and material consumption, passive methods are the most commonly used and developed [1]. Techniques are also used that do not require a change in the structure of the heating surface, such as, for example, wire coils, pipe wrapping with metal net, metal strips. There are also techniques where two or more types of intensification of heat transfer are used simultaneously, called combined methods [2].

Nowadays, researchers pay the highest attention to enhancing of heating surfaces by sintering metallic capillary-porous structures. Such covering is made by a simple technological process that allows to obtain needed characteristics of the structure (porosity and thickness). This method of enhancing the heat exchange surface allows to increase the boiling crisis' heat flux, to obtain high values of heat transfer coefficient and to decrease the temperature of nucleate boiling onset [3]. When enhancing the heat exchange surface by e.g. covering with capillary-porous structure, one has to take into account a hysteresis of heat exchange during the whole range of nucleate boiling [4].

Metallic-fibrous capillary-porous structure is a layer made of wires and heating surface sintered together. These wires are usually made of steel or copper. The diameter of the wires is in the range of $10-100 \mu \mathrm{m}$ and their length is in range of $1-10 \mathrm{~mm}$. The porosity of the surface is in range of 40-86\% and its thickness is between 0.2 and $2 \mathrm{~mm}$. In comparison 
to thermal spraying technique, capillary-porous structure is obtained in a planned manner. This structure can be applied on planar or cylindrical surfaces. The advantage of such a structure is the fact that the its pores are open. The other advantages are possibility to obtain high values of heat transfer coefficient and possibility to applicate the porous structure on surfaces of complex shape [5].

Another way of enhancing the microsurfaceses is by using micofins and minifins. The main advantages of using microfins and minifins are: an increase of heat exchange surface's area, an increase of nucleation sites density and shift of nucleate boiling crisis towards higher heat flux densities [6].

Piasecka, Pastuszko and Strąk [7] have performed a study on the intensification of heat exchange on the surface from microfins. The finned surfaces are additionally covered with perforated foil. Four surfaces with different pore diameters, one without a foil cover and a smooth surface were tested. The working mediums were: ethyl alcohol, distilled water, FC-72 and Novec 649. Dimensions of microfins: length $2 \mathrm{~mm}$, width $1.4 \mathrm{~mm}$ and height $1 \mathrm{~mm}$. The milled microfins were covered with perforated foil by sintering. Pore diameters: $0.3 \mathrm{~mm}, 0.2 \mathrm{~mm}, 0.1 \mathrm{~mm}$ and $0.05 \mathrm{~mm}$. For all liquids boiling excluding ethanol, the highest heat transfer coefficient for the surface with microfins and foil with pores of $0.3 \mathrm{~mm}$ in diameter was obtained. The tests have shown that the ribbed surfaces covered with perforated foil increase the number of nucleation centers, thus increasing the heat transfer coefficient. Depending on the magnitude of the heat flux density, the following results were obtained: at low and medium densities of the heat flux the highest heat transfer coefficients for finned surfaces with perforated foil were obtained, whereas for large heat flux densities for finned surfaces, without foil. Integral structures of tunnel pore type are widely spread and can be found in evaporators of air conditioning and cooling devices.

Structural surfaces, which are enhancements of the Thermoexcel (Hitachi) surface, were investigated by Ghiu and Joshi [8] as well as by Ghiu [9]. The surfaces were crafted by milling two sets of microchannels on a copper plate sized $10 \times 10 \mathrm{~mm}$ and $1 \mathrm{~mm}$ thick. The microchannels were intersecting at $90^{\circ}$ angle. During the experiment channels of width of 0.065-0.47 mm and pitch of 0.2-0.7 mm were used. The working medium was PF 5060. The researchers came up with the conclusion that with the increase of microchannels' width and with the decrease of its pitch heat transfer intensifies. Das et al. [10], [11] introduced a new technology of crafting the structural surfaces by using electroerosion cutting. During water boiling they obtained heat flux densities up to $250 \mathrm{~kW} / \mathrm{m}^{2}$. The conclusion was that the structure with the channels intersecting at the angle of $90^{\circ}$ and cylindrical cavities at their ends intensifies the heat exchange best.

In recent years, nanostructures used to increase the heat transfer intensity during boiling have been the subject of numerous studies.

Passos and Cardoso [12] investigated the boiling of water on nanostructure surfaces. The study analyzed seven heating surfaces: a smooth surface, a rough surface, two heating surfaces with a molybdenum coating, two surfaces with a magnesium coating and a surface created as a result of partial evaporation of magnesium. Nanostructures were created by depositing molybdenum nanoparticles in the process of spraying and depositing magnesium nanoparticles in the evaporation process. Distilled water was used as a working medium and the experiment was carried out at atmospheric pressure. For all the nanostructures, a base surface made of constantan tine tape was used. The hydrophobic surfaces obtain higher heat transfer coefficients, and the surface wettability depends on the configuration of surface defects. The analyzed nanostructures showed a decrease in receding and static contact angle as well as an increase in the critical heat flux compared to surfaces without nanostructures. It was observed that in the initial boiling phase, fewer bubbles occur on nanostructured surfaces, but with larger diameters compared to a smooth substrate. In the case of surfaces covered with a layer of magnesium and molybdenum, the process of their production resulted in differences in roughness. Increasing the roughness occurred on surfaces with a higher amount of deposited material. On the basis of the performed tests, it was shown that nanostructured surfaces have greater wettability due to the greater number of surface defects created by nanoparticles. They affect the contact angle, critical heat flux and heat exchange mechanisms. Maghemitic noanstructural surfaces showed higher roughness and porosity compared to surfaces with molybdenum coating. Maghemite samples have a greater thickness of the nanoparticle layer and wettability than molybdenum samples. Nanostructures led to an increase of critical heat flux, e.g. in the case of a sample coated with a magnesium layer, a higher critical heat flux value by about $139 \%$ was obtained compared to a smooth surface.

Orzechowski [13] investigated heat exchange intensification on a fin with a single and multilayered net. Working medium was water. The experiment was carried out at ambient pressure. Single, dual and triple layered copper net, which was made out of wire $0.18 \mathrm{~mm}$ diameter and $0.55 \mathrm{~mm}$ clearance were investigated. It was proven that the surface covered with the net enables intensification of heat exchange in relation to smooth surface. When dual and triple layered net was used, no increase of heat flux density was observed. This is due to difficulties in the 
movement of steam bubbles caused by hydraulic resistance.

Orzechowski et al. [14] investigated heat exchange on a copper fin covered with capillary-porous structure characterized by parameters: porosity ca. $85 \%$, height $1 \mathrm{~mm}$. Metallic-fibrous structure was made out of wires of $0.5 \mathrm{~mm}$ diameter and $3 \mathrm{~mm}$ length. The working medium was ethanol. The experiment was carried out at the ambient pressure. In order to compare results, the experiment was also carried out with plain (smooth) fin. The onset of nucleate boiling in the case of fin covered with the structure was observed at superheat of $8 \mathrm{~K}$ and in case of plain fin at $3.5 \mathrm{~K}$. Based on calculations it was shown that for the superheat of $19 \mathrm{~K}$ the difference of heat flux density between smooth and capillary-porous structure is the highest and equal to $217.7 \mathrm{~kW} / \mathrm{m}^{2}$.

Another way of enhancing heat exchange surfaces is by using narrow channels. This method requires proper selection of channels' width depending on the spatial configuration, magnitude of heat flux density and working medium. Such structures are used for cooling micro heat exchangers or electronic components [6].

Passos [15], Misale [17] and Stutz [16] carried out experiments in horizontal narrow channels. Passos [15] observed an increase of heat transfer coefficient along with the decrease of channels' height, while Stutz [16] and Misale [17] observed the largest values of heat transfer coefficients for the highest channels. Fujita [18] was investigating impact of channels' width on heat transfer coefficient during boiling. He came up with a aconclusion that a decrease of the channels' width (up to $0.6 \mathrm{~mm}$ ) results in an increase of the heat transfer coefficient.

Microchannels etched in silicon plates sized $10 \times 10 \mathrm{~mm}^{2}$ are used for an intensification of heat transfer during boiling. Cooke and Kandlikar [19] carried out experiments with microchannels of 60-200 $\mu \mathrm{m}$ width and 180-275 $\mu \mathrm{m}$ depth. Working medium was water. They obtained a 3.4-fold increase of heat transfer coefficient in relation to smooth surface. The largest value was obtained for a microchannel with cross section sized $100 \times 275 \mu \mathrm{m}$. Cooke and Kandlikar [20] one year later obtained a better results for microchannels of 200-400 $\mu \mathrm{m}$ width and 100-400 $\mu \mathrm{m}$ depth. The microchannels were crafted in copper plates sized $10 \times 10 \mathrm{~mm}^{2}$. The highest value of heat transfer coefficient, equal to ca. $270 \mathrm{~kW} / \mathrm{m}^{2} \mathrm{~K}$, was obtained for cross section sized $375 \times 400 \mu \mathrm{m}$.

Similar results were obtained by Guan et al. [21] for channels $400 \mu \mathrm{m}$ wide and $600 \mu \mathrm{m}$ deep modified with circular extensions of diameter 600-1000 $\mu \mathrm{m}$ and pitch of 1.9-24 mm for selected channels. By using the smallest diameters and pitch the highest efficiency was achieved.
Seo, Lim, Shin, and Bang [22] carried out experiments of pool boiling on a heating surface modified by addition of holes of various dimensions. The experiments were carried out at atmospheric pressure. The working medium was deionized water. Four types of heating surfaces were considered: plain (i.e., no holes), 9, 49, and 225-hole surfaces For the holed surfaces, increase of heat transfer in relation to plain surface by $9.8 \%, 26 \%$ and $26 \%$ respectively was observed. For these surfaces, lower temperatures and higher heat fluxes were also observed. This is indication, that the heat transfer was more efficient for hole-patterned surface than for plain surface.

Many publications focus on ways to intensify heat transfer by applying coatings with complicated structure. Application of simple enhancements of heat exchange surfaces, like drilling cavities, in order to intensify heat transfer in some cases is advisable. Such modifications, although not as efficient in terms of heat transfer capabilities, can be attractive is cases of solutions boiling, in which solute can deposit on heat exchange surface. Such situations occur in food, chemical and cosmetics industries. Investigation of surfaces modified by simple, and therefore easy to clean, enhancements is advisable, despite their smaller efficiency in terms of heat transfer.

\section{EXPERIMENTAL STAND}

The main module of the laboratory stand consists of a brass plate, which one side is a heating surface. The plate is connected with a brass cuboid acting as a thermal buffer. Four heating resistors with a silicone paste reducing the thermal contact resistance were screwed to the cuboid. In order to minimize heat loss, insulation around the heating element was used. The rigid tripod ensured the stability of the main module. A glass cylinder made of borosilicate glass provided adequate thermal resistance and conditions for the recording of the boiling process. Proper placement of the thermocouples ensured obtaining data necessary to calculate the heat transfer coefficient. The heating element was selected after calculating the electrical power needed to supply the system based on the thermal balance of the system.

The stand equipment includes: cooler 7 (Fig. 1-2, Tab. 1), pressure transmitter, computer, TDK Lambda 3 power supply, measurement data acquisition system 4 , camera 5 and lighting 6 . The camera used in the stand is a Phontom v711 Vision Research high speed camera with a resolution of $1280 \times 800$ and a speed of 7530 frames per second. The Hedler HF65 halogen lamp provided the right lighting. A measuring system based on National Instruments modules was used: NI cDAQ-9172 - main module and NI 9211 temperature measurement. 


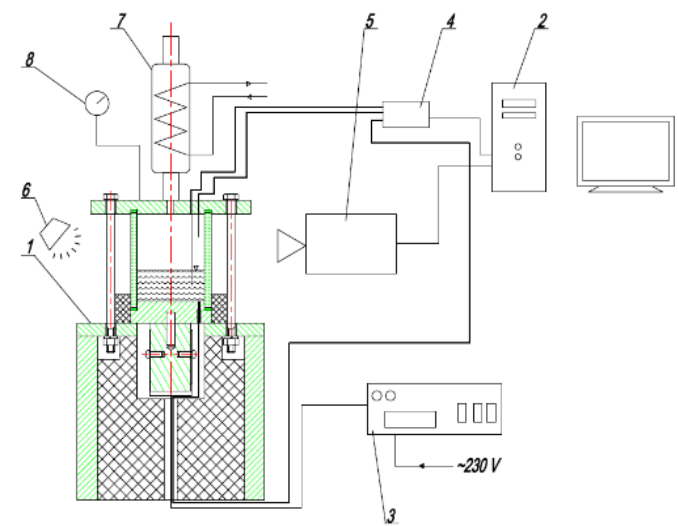

Fig. 1. Schematic diagram: 1 - main module, 2 - computer, 3 - power supply, 4 - measuring system, 5 - camera, 6 - lamp, 7 - cooler, 8 - manometer

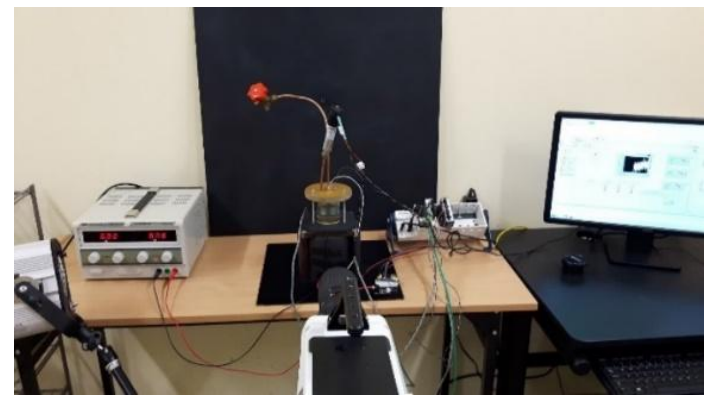

Fig. 2. A photo of the laboratory stand

\subsection{Measurement data acquisition system}

Control and measurement software has been developed in the LabView environment (Fig. 3). The control panel window is a graphical interface between the user and the program. The use of appropriate components such as displays and switches allows to control the hardware part of the stand as well as perform calculations of the experiment parameters. The source code is graphic and performs the functions of a virtual instrument. The main part of the application is implemented in a loop to ensure the continuity of reading and writing of data: pressure, temperature, current and voltage, calculation of power and heat flux density.

The use of the high speed camera was difficult because the camera manufacturer did not develop any properly working drivers enabling direct operation of the camera in LabView applications. An indirect method has been developed to facilitate the recording of video images and static images from the camera to the computer disk. The block named Property Node and the system clipboard were used to automatically generate file names containing information about the basic parameters of the experiment.

Tab. 1. Thermo-physical properties of the fluids

\begin{tabular}{|c|c|c|c|c|}
\hline Medium & $\begin{array}{l}\text { Density } \\
{\left[\frac{\mathrm{kg}}{\mathrm{m}^{3}}\right]}\end{array}$ & $\begin{array}{c}\text { Heat of } \\
\text { evaporation } \\
{\left[\frac{\mathrm{J}}{\mathrm{kg}}\right]}\end{array}$ & $\begin{array}{c}\text { Specific heat } \\
{\left[\frac{\mathrm{J}}{\mathrm{kgK}}\right]}\end{array}$ & $\begin{array}{c}\text { Boiling temperature, } \\
{\left[{ }^{\circ} \mathrm{C}\right]}\end{array}$ \\
\hline Ethyl alcohol & 789 & 841500 & 2390 & 78.3 \\
\hline Isopropyl alcohol & 785 & 663900 & 2570 & 82.4 \\
\hline
\end{tabular}

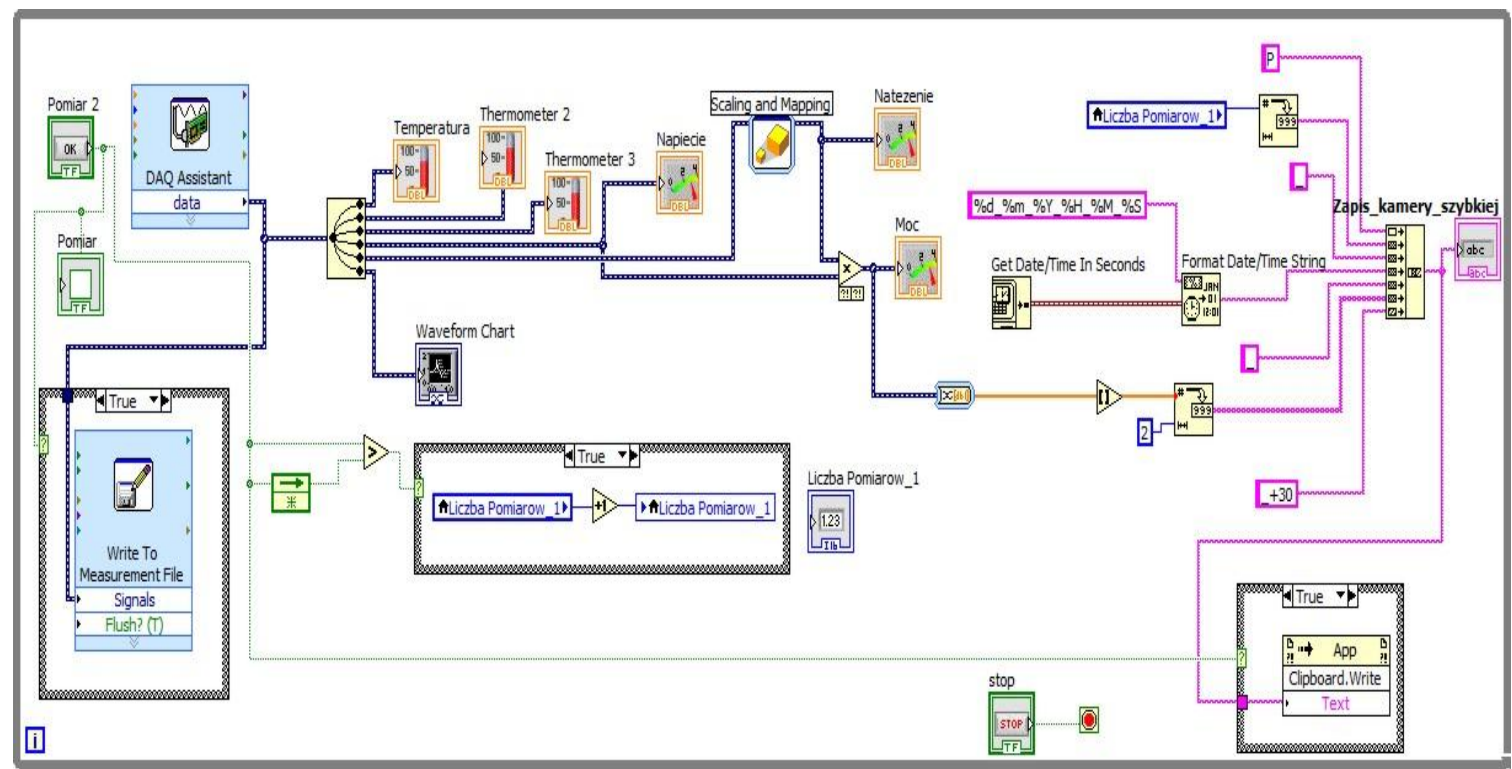

Fig. 3. LabView application block diagram 


\subsection{Enhancing heating surfaces}

An experimental study was carried out for three enhanced surfaces. The diameters of the samples were $50 \mathrm{~mm}$, they were made of brass. The surface of the sample No. I was machined (turning). The surface of sample No. II was enhanced by drilling holes with a diameter of $2 \mathrm{~mm}$ at distances of 1.4-1.6 mm. 133 holes were drilled. Drilling depth: $1.5 \mathrm{~mm}$. The surface of sample No. III was enhanced by drilling holes with a diameter of $3 \mathrm{~mm}$ at distances of 2.9$3.2 \mathrm{~mm}$. 61 holes were drilled. Drilling depth: $1.5 \mathrm{~mm}$.

Tab. 2 presents the samples, photos and drawings of the base samples discussed. $R a$ denotes average surface roughness.

Tab. 2. Types of enhancements of heating surfaces
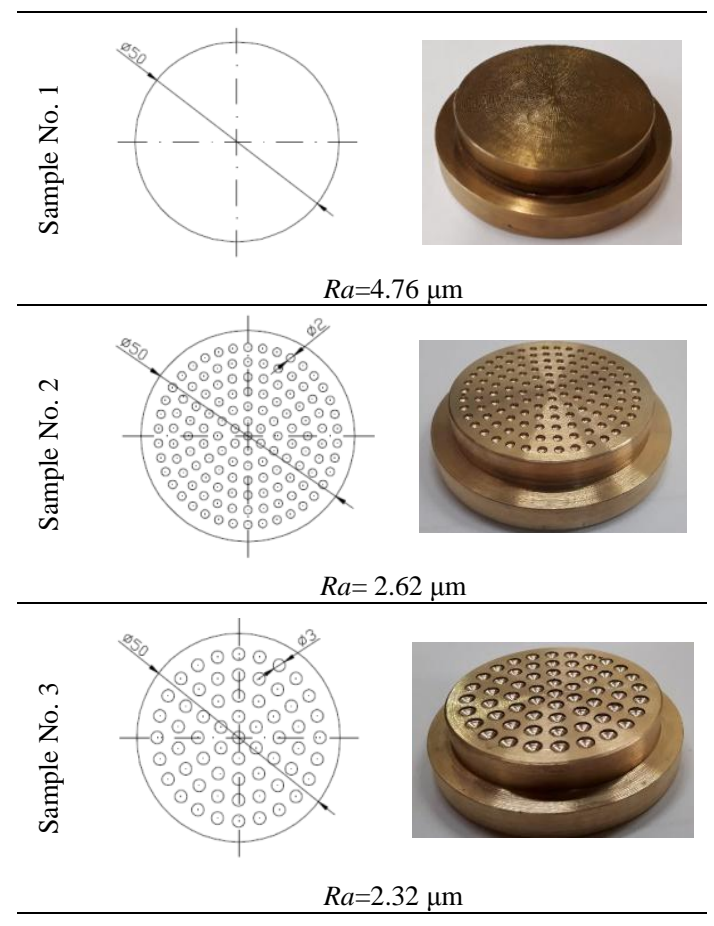

\subsection{Calculation of heat flux density and heat transfer coefficient}

The heat flux density can be determined on the basis of the heat balance of the stand. From the balance one obtains an equation:

$$
q=\frac{P_{e l}-\dot{Q}_{s}}{F}\left[\frac{W}{m^{2}}\right] .
$$

With an omission of small heat losses to the environment: $\dot{Q}_{\mathrm{s}} \cong 0$ heat transfer coefficient $(\alpha)$ can be determined from the following equation:

$$
\alpha=\frac{q}{\Delta T}\left[\frac{W}{m^{2} K}\right] .
$$

Heat exchange area was calculated as:

$$
F=\pi R^{2}-n \pi r^{2}+\mathrm{n}\left(2 \pi r h_{1}+\pi r \sqrt{h_{2}^{2}+r^{2}}\right),
$$

where:

$R$ - sample (plate) radius,

$r$-radius of the hole,

$n$ - number of holes,

$h_{1}$ - height of the cylindrical part of the hole,

$h_{2}$ - height of the conical part of the hole.

An important role in vapor bubbles generation play heat exchange surface's edges. The parameter which characterizes edges occurrence density can be defined as:

$$
W=\frac{L_{k}}{\mathrm{~F}},
$$

where:

- edge length reads:

$$
l_{k}=2 \pi r,
$$

- total length of all edges reads:

$$
L_{k}=n \cdot 2 \cdot l_{k}+2 \pi R .
$$

Fig. 4 shows dimensions of sample and holes.

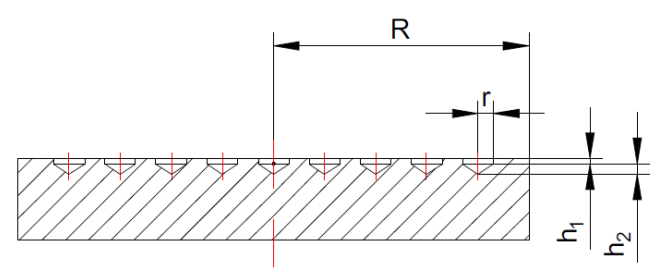

Fig. 4. Dimensions of sample and holes

\subsection{Void fraction}

In order to determine the void fraction, a calculation procedure using CorelDraw, Corel PhotoPaint and LabView Vision Assistant software was used. Photos from visualization tests were processed in Corel Draw and Corel PhotoPaint, and then the LabView Vision Assistant was used to determine the areas occupied by the vapor phase.

The void fraction was calculated by summing the surface area of all objects (bubbles) and dividing by the surface area of the obtained image. When analyzing the image, it was attempted to choose a fixed plane to which the optical system of the camera was tuned and in which the number and size of steam bubbles were analyzed.

\section{DETERMINATION OF MEASUREMENT ERROR}

In order to obtain a small error value in the measuring system, high accuracy sensors were used. The Czaki thermocouples cooperating with the NI 9211 module were calibrated, which resulted in a temperature measurement limiting error of $0.55 \mathrm{~K}$. 

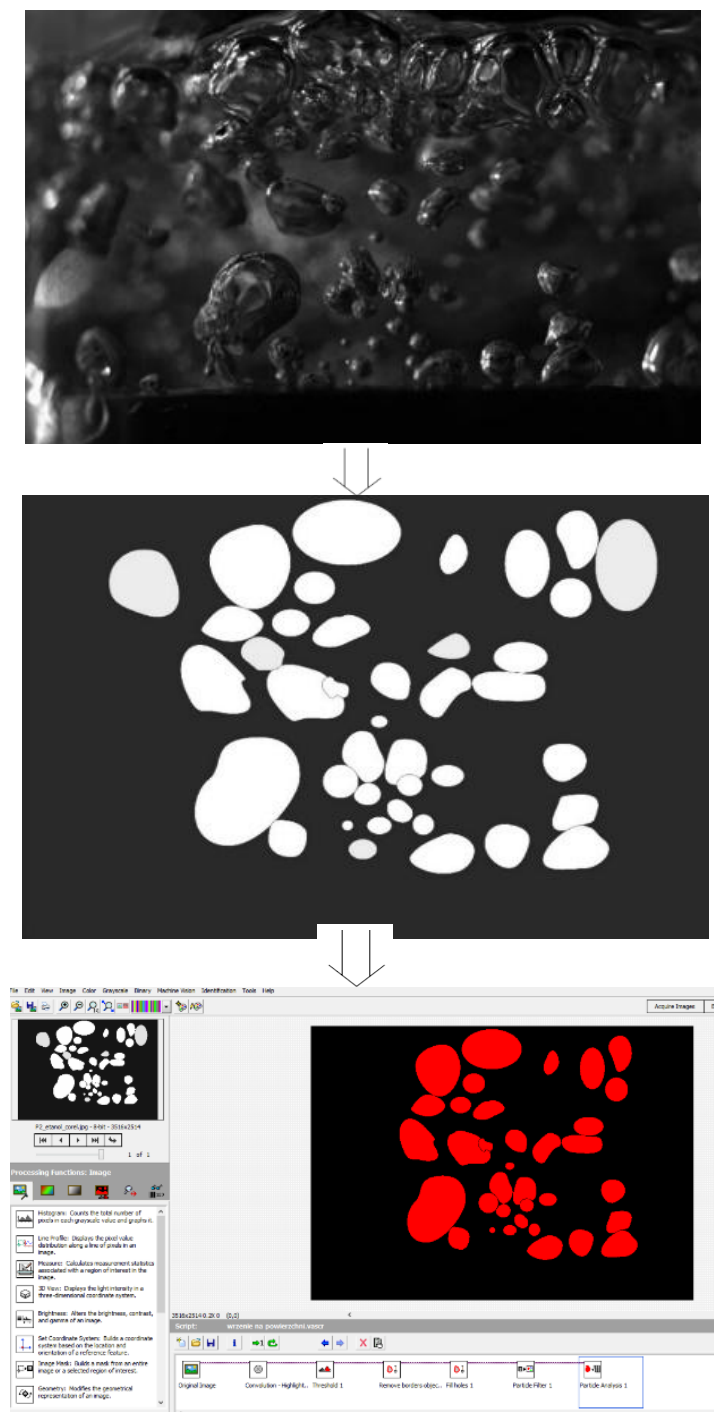

Fig. 5. LabView Vision Asisstant program screen with the image processing procedure

To measure the voltage and the current supplying the heater, the TDK Lambda internal measuring system was used for which the reading error was $0.1 \%$ of the measured value. The complete differential method was used to estimate the resulting measurement error of the heater power and the heat transfer coefficient. Maximum relative error values are for the heater's electrical power $0.2 \%$ and for heat transfer coefficient $21.6 \%$.

When determining the void fraction, measurement error of photographic techniques can reach significant values and is difficult to determine. In this paper, it has not been analyzed.

\section{EXPERIMENTAL RESULTS}

Based on Fig. 6 a), it was found that for sample No. II (pre-drilled 133 holes $\Phi 2 \mathrm{~mm}$ ) higher values of the heat flux density were obtained and the boiling onset takes place at lower overheating compared to the other heating surface enhancements. The ratio of heat flux density values for individual surfaces at overheating $\Delta T=3.6 \mathrm{~K}$ amounts to: $q_{I I} / q_{I}=1.27$, $q_{I I} / q_{I I I}=1.25$. For all the samples, the heat flux density increases with overheating. On the basis of Fig. 5 b) it can be concluded that for sample No. III (predrilled 61 holes $\Phi 3 \mathrm{~mm}$ ) the is a gradual increase in the value of $\alpha$, while in the case of the other surfaces $\alpha$ declines.

Increase of heat transfer coefficient for $\mathrm{q}=40 \mathrm{~kW} / \mathrm{m}^{2}$ amounts to: $q_{I I} / q_{I}=2.18, q_{I I} / q_{I I I}=2.20$. As the heat flux density increases, the heat transfer coefficient for samples 2 and 3 increases, while for sample 1 it is approximately constant. A fairly large measurement error for the value of $\alpha$ may be difficult to interpret, but the tendency of parameters values variation is possible to determine A similar tendency of variation for $\mathrm{q}(\Delta \mathrm{T})$ and $\alpha(\mathrm{q})$ values in cases of deionized water boiling on open surfaces was observed by Seo, Lim, Shin, and Bang [22].

In the case of sample No. 2 for isopropyl alcohol, the trend differs from the trends of variations for the remaining samples. Interpretation of this phenomenon requires further research, where extended range of holes number as well as other working mediums will be investigated.

The results of the heat flux density as a function of overheating for isopropyl alcohol are presented in Fig. 7.

On the basis of Fig. 7 a), it can be concluded that for all the samples proportional values of heat flux density were obtained, but for sample No. II this occurred at lower overheating. The ratio of heat flux density values for individual surfaces at overheating $\Delta T=3.6 \mathrm{~K}$ amounts to: $q_{I I} / q_{I}=1.6, q_{I I} / q_{I I I}=1.3$. For all the samples, the heat flux density increases with overheating.

For sample No. II, the highest values of $\alpha$ were obtained with small overheating, but as the overheating increases, the value of $\alpha$ gradually decreases. For sample No. III, boiling was initiated at a higher superheat temperature than in case of surface No. II, but smaller than in the case of surface No. I. It can be concluded that for sample No. II the increase of $\alpha$ occurs with overheating. Increasing the value of the heat transfer coefficient informs about intensification of heat exchange.

Increase of heat transfer coefficient for $q=40$ $\mathrm{kW} / \mathrm{m}^{2}$ amounts to: $q_{I I} / q_{I}=1.9, q_{I I} / q_{I I I}=1.6$. For sample No. III, a slight increase in the heat transfer coefficient was observed along with the increase of the heat flux density, similarly in the case of sample No. I. In contrast, for sample No. II, along with the increase in the value of the heat flux density, the heat transfer coefficient value decreases. 
a)

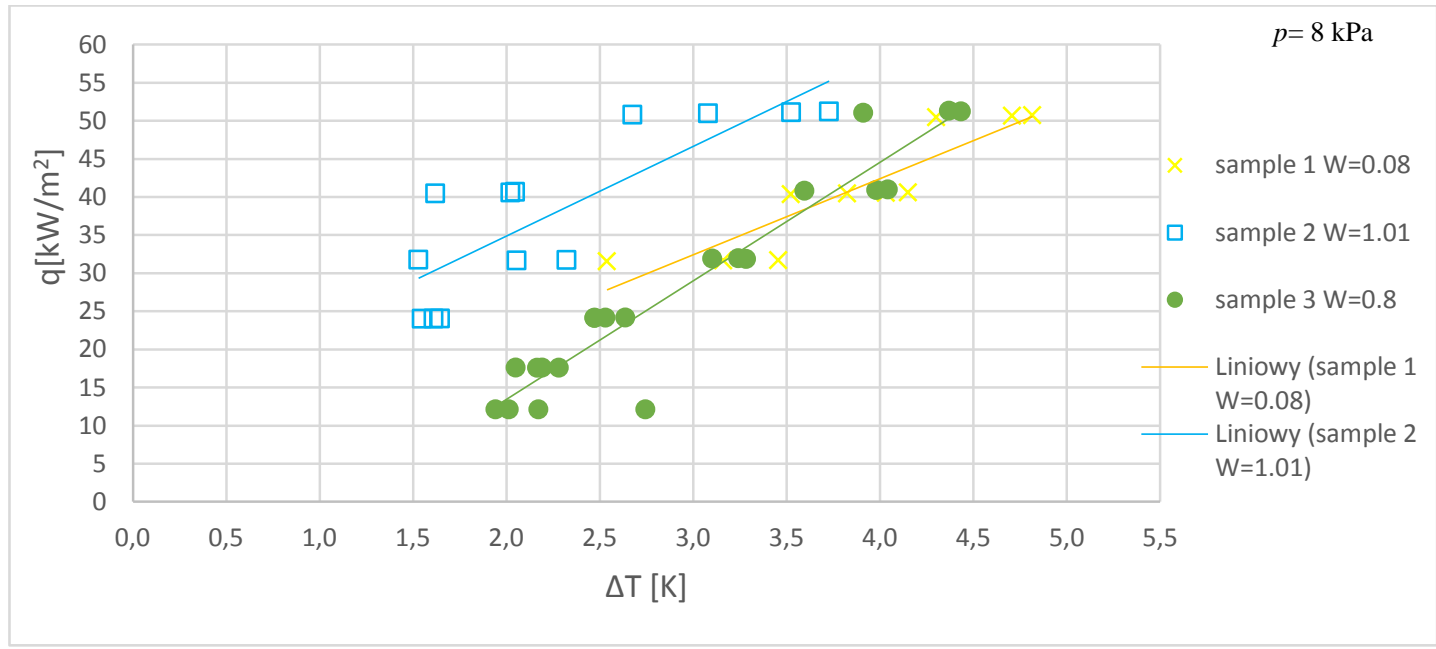

b)

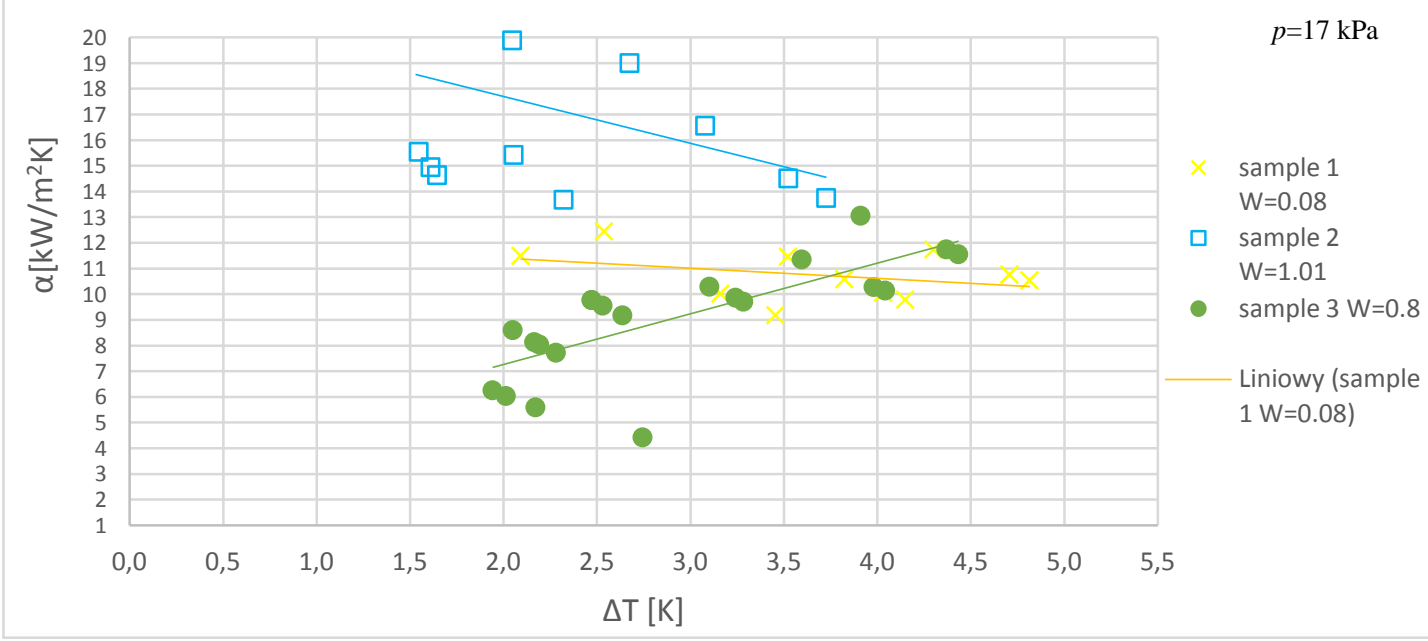

c)

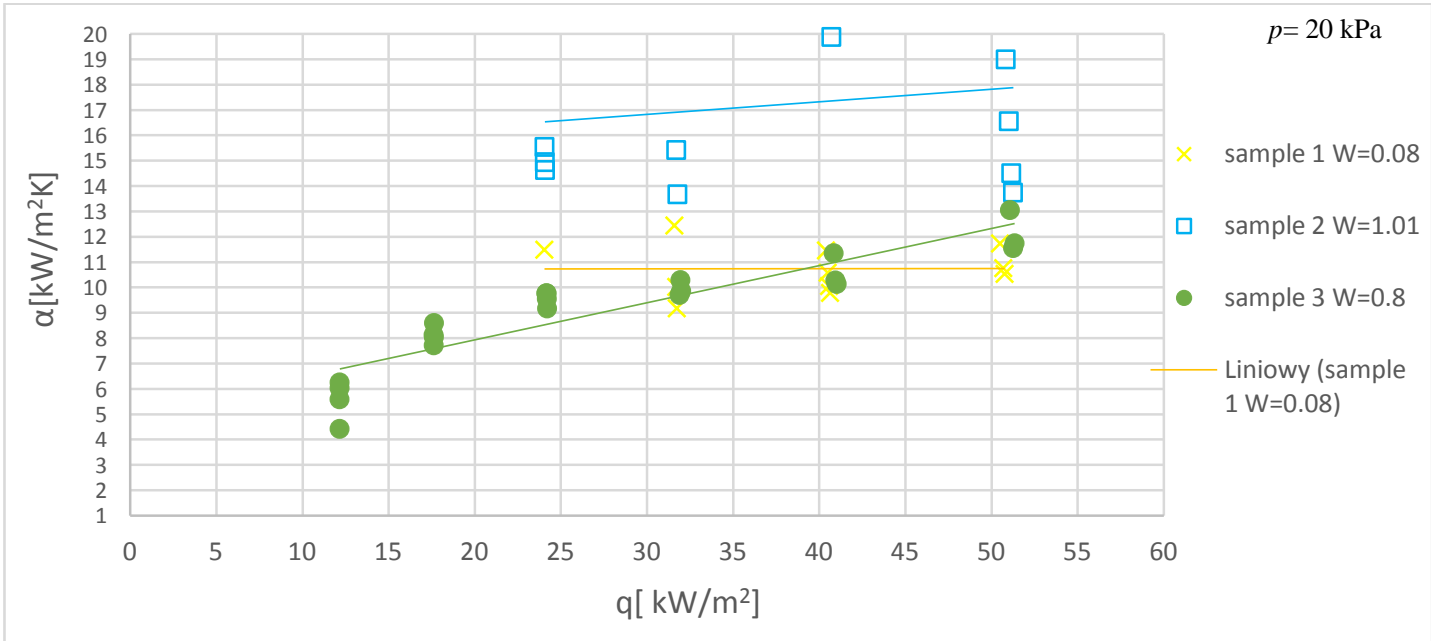

Fig. 6. Test results for ethyl alcohol a) dependence of the heat flux density on overheating b) dependence of the heat transfer coefficient on overheating c) dependence of the heat transfer coefficient on the heat flux density 
a)

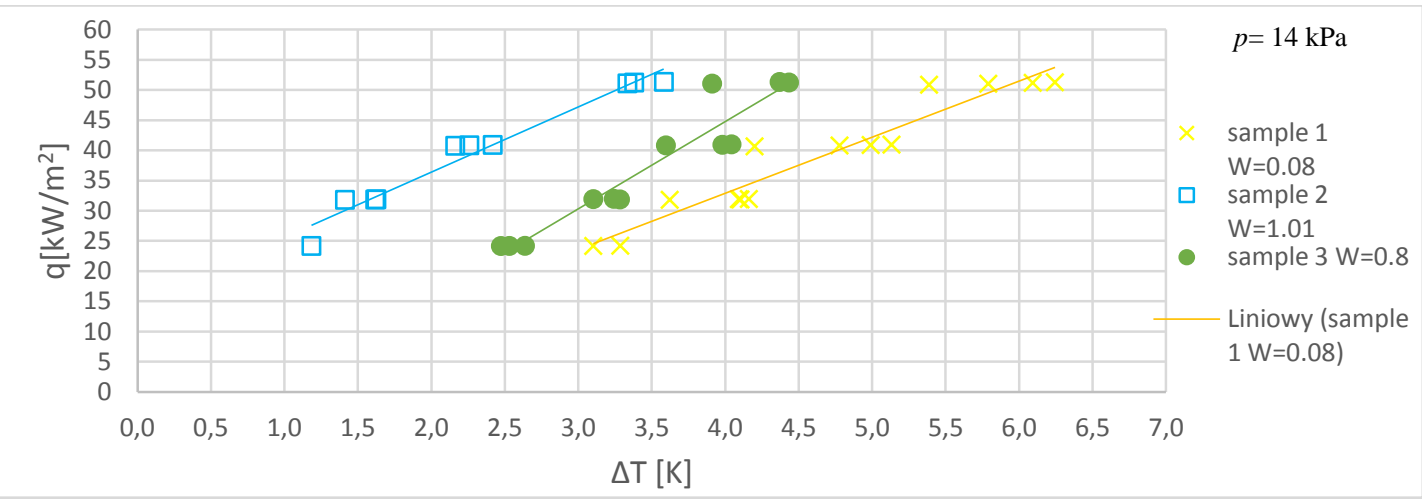

b)

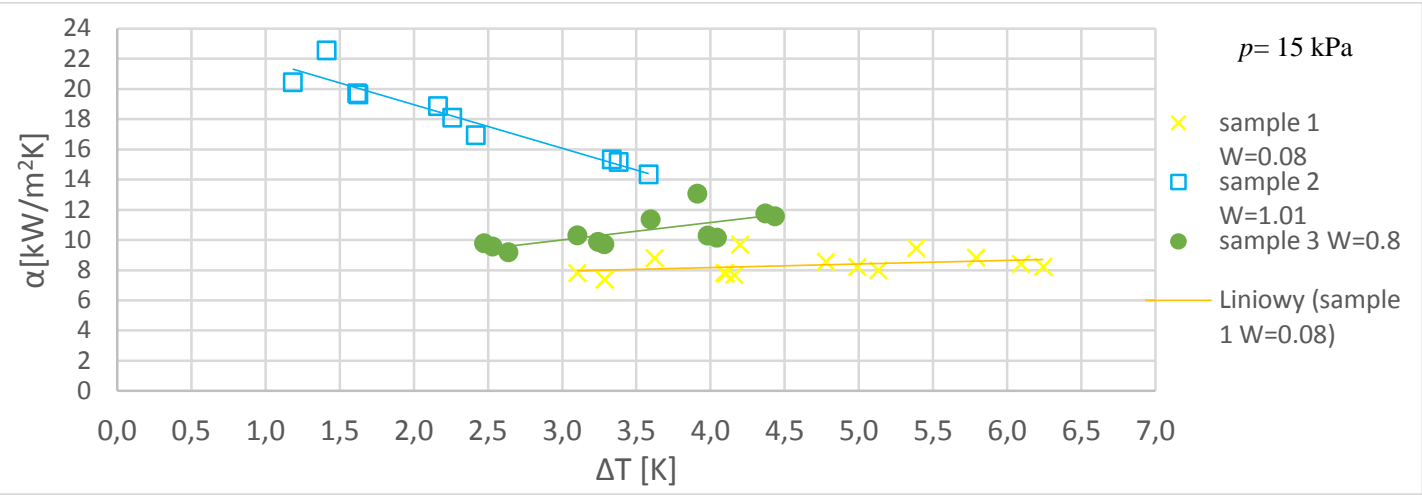

c)

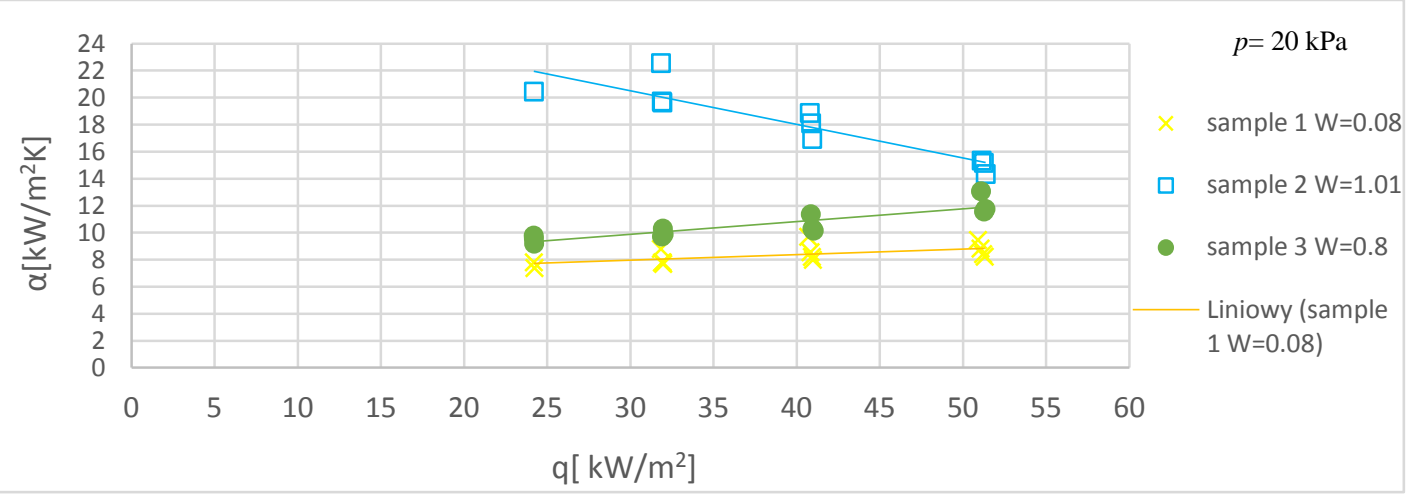

Fig. 7. Test results for isopropyl alcohol a) dependence of the heat flux density on overheating b) dependence of the heat transfer coefficient on overheating c) dependence of the heat transfer coefficient on the heat flux density

\section{CONCLUSIONS}

On the basis of the diagrams drawn of the dependence of the heat transfer coefficient on overheating, it can be concluded that the highest values were obtained for sample No. II for both isopropyl alcohol and ethanol. The surface of this sample was developed by drilling holes with a diameter of $2 \mathrm{~mm}$ at distances of 1.6-1.9 $\mathrm{mm}$. It can be clearly stated that surfaces enhanced by drilling in comparison to the surface without holes with $R a=4.76 \mu \mathrm{m}$ intensify heat exchange during boiling.
The main factors affecting the intensity of heat exchange are the type of enhanced surface and the working medium.

The void fraction was determined using the LabView Vision Assistant software and recorded images. The highest void fraction was obtained for sample No. I, 0.22. It should be noted that photographic methods can be burdened with a large and difficult to estimate error.

In experiments based on sample No. I ( $R a=4.76$ $\mu \mathrm{m}$, without holes) the largest bubbles were observed. Coalescence of the bubbles was also observed. In the 
Tab. 3. Recorded test results for ethanol and isopropanol for sample I, II and III

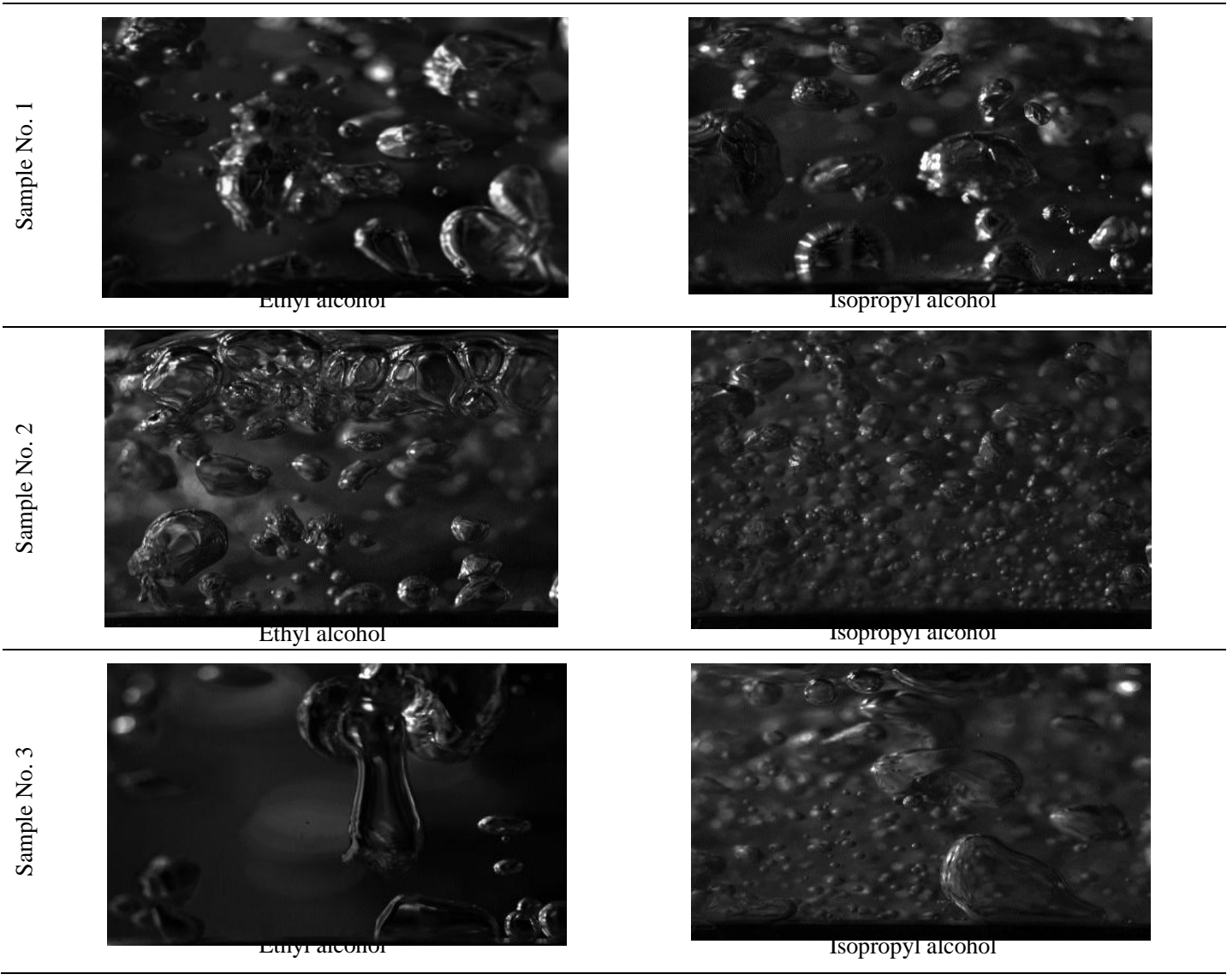

a)

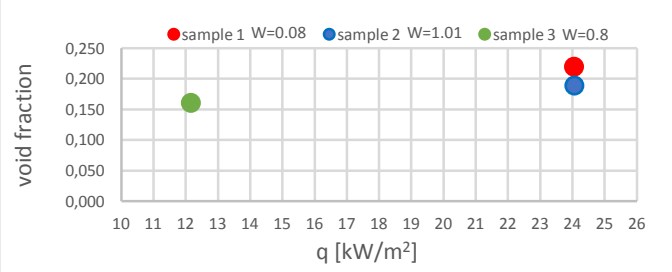

b)

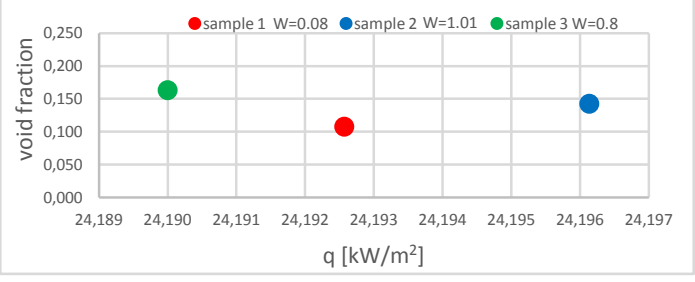

Fig. 8. The dependence of the average void fraction on the density of the heat flux: a) ethanol; b) isopropanol

case of experiments based on sample No. II ( $R a=2.62$ $\mu \mathrm{m}, 133$ holes with diameter of $2 \mathrm{~mm}$ ), small vapor bubbles in a significant amount were observed. In experiments based on sample No. III $(R a=2.32 \mu \mathrm{m}$, 61 holes with diameter of $3 \mathrm{~mm}$ ) larger vapor structures were obtained than in the case of the previous samples. Large bubbles formed on the edges of the plate and smaller bubbles formed in the central part of the sample.

Comparing average void fraction for the experiments carried out at comparable heat flux densities, it can be observed that for isopropyl alcohol the highest void fraction was obtained for sample No. III with value of 0.163 . In the case of ethyl alcohol, the highest void fraction was obtained for sample No. I with value of 0.22 (Fig 8).

Vapor structures obtained for isopropyl alcohol are in most cases smaller compared to the structures obtained for ethyl alcohol (Tab. 3). The sample that generated the smallest structures is the sample No. II. The obtained results of the heat transfer coefficient confirm its highest efficiency among the samples tested.

Visualization studies enabled the observation of the variability of the boiling process, observations of its individual phases, and a comparison of obtained vapor structures for individual surface enhancements and working mediums. Further experiments are planned using a modified laboratory stand that would reduce the measurement error of image analysis techniques. 


\section{Nomenclature}

\section{Symbols}

$F \quad-$ heat exchange area, $\mathrm{m}^{2}$

$p \quad-$ working pressure, $\mathrm{Pa}$

$P_{e l} \quad-$ electric power of the heater, W

$q \quad$ - heat flux, $\mathrm{W} / \mathrm{m}^{2}$

$\dot{Q}_{S} \quad-$ heat loss stream, $\mathrm{W}$

$\Delta T \quad$ - overheating, $\mathrm{K}$

\section{Greek letters}

$\alpha \quad-$ heat transfer coefficient, $\mathrm{W} / \mathrm{m}^{2} \cdot \mathrm{K}$

\section{References}

1. Piasecka M. (2014). Wrzenie w przepływie na rozwiniętych powierzchniach minikanałów. Wydawnictwo Politechniki Świętokrzyskiej, Kielce.

1. Poniewski M. E. (2001) Wrzenie pęcherzykowe na rozwiniętych mikropowierzchniach. Monografie, studia, rozprawy nr 23, Wydawnictwo Politechniki Świętokrzyskiej, Kielce.

2. Wójcik T. M., Kaniowski R., Mroczek P. J. (2005). Wizualizacja wrzenia na mikropowierzchniach rozwiniętych. Pomiary Automatyka Kontrolna, t. 5, s. 31-35.

3. Cieśliński J.T. (2005). Modelowanie wrzenia pęcherzykowego. Wydawnictwo Politechnika Gdańska, Gdańsk.

4. Wójcik M.T. (2010). Inicjacja wrzenia I histereza wymiany ciepła na pokryciach porowatych. Rozprawy monografie 204, Wydawnictwo AGH, Kraków.

5. Pastuszko R. (2001). Wymiana ciepła przy wrzeniu w tunelach podpowierzchniowych. Monografie, studia, rozprawy nr M33, Wydawnictwo Politechniki Świętokrzyskiej, Kielce.

6. Pastuszko R., Piasecka M., Nadstawna E. (2014). Badanie intensyfikacji wymiany ciepła podczas wrzenia pecherzykowego. Logistyka 6/14, s. 7746-7754.

7. Ghiu C.D., Joshi Y.K. (2005). Boiling performance of single-layered enhanced structure. Journal of Heat Transfer, Vol. 127, pp. 675-683.

8. Ghiu C.D. (2007). Pool boiling from enhanced structures under confinement. Ph.D. dissertation. Georgia Institute of Technology.

9. Das A.K., Das P.K., Saha P. (2009). Performance of different structured surfaces in nucleate pool boiling. Applied Thermal Engineering, Vol. 29, pp. 3643-3653.

10. Das A.K., Das P.K., Saha P. (2010). Some investigations on the enhancement of boiling heat transfer from planer surface embedded with continuous open tunnels. Experimental Thermal Fluid Science, Vol. 34, pp. 14221431.

11. Heitich L.V., Passos J.C., Cardoso E.A. (2013). Nucleate boiling of water using nanostructured surfaces. Journal of the Brazilian Society of Mechanical Sciences and Engineering, Vol. 36, pp. 181-192.

12. Orzechowski T. (2003). Wymiana ciepła przy wrzeniu na żebrach z mikropowierzchnią strukturalną. Wydawnictwo Politechniki Świętokrzyskiej, Kielce.

13. Orzechowski T., Tyburczyk, Ziętala K. (2014). Wymiana ciepła przy wrzeniu na żebrze $\mathrm{z}$ pokryciem metalowowłóknistym. Zeszyty naukowe Politechniki Rzeszowskiej 290, Mechanika 86, RUTMech, t. XXXI, z. 86(2/14), s. 231-238.

14. Passos J. C., Possamai L.F.B., Hirata F.R. (2005). Confined and unconfined FC-72 and FC-87 boiling on a downward-facing disc. Applied Thermal Engineering, Vol. 25, pp. 2543-2554.
15. Stutz B., Lallemand M., Raimbault F., Passos J. (2009). Nucleate and transitions boiling in narrow horizontal spaces. Heat Mass Transfer, Vol. 45, pp. 929-935.

16. Misale M., Guglielmini G., Priarone (2011). Nucleate boiling and critical heat flux of HFE-7100 in horizontal narrow spaces. Experimental Thermal Fluid Science, Vol. 35, pp.772-779.

17. Fujita Y., Ohta H., Uchida S., Nishikawa K. (1988). Nucleate boiling heat transfer and critical heat flux in narrow space between rectangular surfaces. Journal of Heat Mass Transfer, Vol. 31, pp. 229-239.

18. Cooke D., Kandlikar S.G. (2011). Pool boiling heat transfer and bubble dynamics over plain and enhanced microchannels. Journal of Hear Transfer, Vol. 133, pp. 052902-052909.

19. Cooke D., Kandlikar S.G. (2012). Effect of open microchannel geometry on pool boiling enhancement. Journal of Hear Mass Transfer, Vol. 55, pp. 1004-1013.

20. Guan N., Liu Z.-G., Takei M., Zhang C.-W. (2010). Boiling heat transfer in microcapillary grooves with different structured surfaces of microcavities. Experimental Heat Transfer, Vol. 23, pp. 217-234.

21. Seo H., Lim H., Shin H., Bang I. Ch. (2018). Effects of hole patterns on surface temperature distributions in pool boiling. International Journal of Heat and Mass Transfer, 120 , pp. $587-596$

\section{Biographical note}

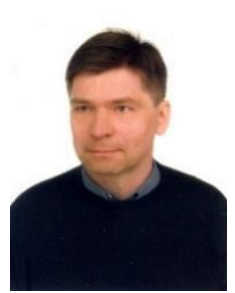

Mirosław Grabowski graduated from the Faculty of Power and Aeronautical Engineering of Warsaw University of Technology (1992). He received his PhD degree at Warsaw University of Technology, Faculty of Civil Engineering, Mechanics and Petrochemistry (2002). From 2003 is the Head of the Thermal Engineering Laboratory of the Warsaw University of Technology, Faculty of Civil Engineering, Mechanics and Petrochemistry. His scientific interests focus on issues related to the thermal technology, research on boiling and condensing, especially in flows in minichannels as well as research on new insulating materials.

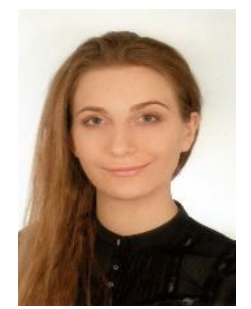

Ewelina Blachnio received the title of engineer in the field of Mechanics and Machine Design at the Faculty of Civil Engineering, Mechanics and Petrochemistry of the Warsaw University of Technology. She graduated in mechanical engineering and will defend in March this year. Her scientific interests include heat exchange, nucleate boiling and intensification of heat exchange during boiling on developed surfaces. 